\title{
A APROPRIAÇÃO DO CONCEITO COMO OBJETO NA LITERATURA PERIÓDICA CIENTÍFICA EM CIÊNCIA DA INFORMAÇÃO
}

\author{
LA APROPIACIÓN DEL CONCEPTO EN CUANTO OBJETO DE LA \\ LITERATURA CIENTÍFICA EN CIENCIA DE LA INFORMACIÓN
}

\author{
Leilah Santiago Bufrem - leilah@ufpr.br \\ Doutora em Ciência da Comunicação pela Universidade de \\ São Paulo. Pós-Doutora pela Universidad Autónoma de \\ Madrid. Professora Titular do Departamento de Ciência e \\ Gestão da Informação da Universidade Federal do Paraná, \\ Curitiba, Paraná, Brasil. \\ Rene Faustino Gabriel Junior - rene@sisdoc.com.br \\ Doutorando em Ciência da Informação na Unesp de Marília, \\ Mestre em Ciência, Gestão e Tecnologia da Informação pela \\ Universidade Federal do Paraná e Bacharel em \\ Biblioteconomia pela PUCPR, Curitiba- Paraná- Brasil
}

\begin{abstract}
Resumo
Analisa a noção de conceito situada na literatura periódica em Ciência da Informação no Brasil. Problematiza as concepções teóricas sobre o conceito e suas relações com o processo histórico que o determina, assim como indica possibilidades de estudos relativos aos campos semânticos em que se efetivam essas relações. Analisa o conteúdo de um corpus de 75 artigos, selecionados da Base Referencial de Artigos de Periódicos em Ciência da Informação (Brapci), entre os anos de 1975 e 2011, identificando e mapeando categorias temáticas relacionadas à concepção e à evolução do conceito, como objeto de estudo. O conceito é discutido amplamente em relação as suas origens filosóficas e as suas relações com as ciências e com a realidade, mas ainda não tem sido suficientemente explorado no que se refere à riqueza e às conotações que adquire historicamente, à ideologia ou às relações de força existentes nos campos semânticos em que é representado e definido.
\end{abstract}

\section{Palavras-chave}

Conceito. Teoria do Conceito. Terminologia. Modelo Conceitual. 


\section{INTRODUÇÃO}

Pode-se afirmar que, na extensa história da filosofia, sempre esteve evidente a ligação entre a linguagem, da qual nos servimos para a comunicação, e a realidade por ela representada. A linguagem transmite informações, expressa sentimentos e atitudes, mas revela igualmente contradições, ideologias, paixões e contrastes, nem sempre de forma unívoca, às vezes até equivocada ou preconceituosamente marcada. Para fins deste estudo, importa aproximá-la do núcleo da Ciência da Informação $(\mathrm{Cl})$, destacandose suas tendências teóricas em relação às representações do "conceito" na literatura periódica publicada no Brasil. Focam-se, portanto, os modos de aproximação ao conceito, aqui compreendido como forma de pensamento que permite captar os caracteres gerais e essenciais das coisas e dos fenômenos da realidade objetiva (KHLYABICH, 1967).

Para melhor compreensão do objeto "conceito", há correntes da filosofia da linguagem que favorecem seu entendimento, destacando-se, no corpus selecionado para este trabalho, aquelas relacionadas à filosofia analítica, voltada à análise do significado dos conceitos e proposições (FREGE, 1967); ao neopositivismo e Círculo de Viena (OLIVEIRA, 2010); à chamada filosofia linguística, pela qual os conceitos são definidos pela prática linguística, e à gramática da linguagem natural, representada por Chomsky (2006), que admite universais linguísticos presentes em todas as línguas.

Se aceita a concepção de "conceito" como aquilo que a mente concebe ou entende, ou seja, uma noção ou representação geral de uma realidade concreta, tem-se o "termo" como a representação da representação, associada a um objeto do universo de discurso ou a uma unidade semântica. Desse modo, os conceitos seriam portadores de significado e universais por se aplicarem igualmente a todas as coisas em sua extensão. As representações expressas por meio de conceitos são determinadas pela realidade, mas por outro lado são determinantes em relação aos termos definidos, devido às relações necessárias e obrigatórias entre a natureza, o conhecimento e os elementos representativos da realidade.

Essa relação, aparentemente simples, apresenta-se em muitas áreas do conhecer e agir, como a matemática, a filosofia, as ciências cognitivas, a física e a informática. Um único conceito pode, entretanto, ser expresso em diversas linguagens e, assim, termos distintos podem representá-lo. Da mesma forma, termos idênticos podem se referir a conceitos diversos. A busca do rigor no emprego de termos, consequentemente, tem sido uma constante não exclusiva à área de organização do conhecimento, conforme analisa 
Francelin (2011), ao discutir a questão da legitimidade no uso de conceitos além de seus campos de fixação. Entendendo que a imposição de barreiras e, ao mesmo tempo, a falta de rigor na apropriação de conceitos isola e fragiliza o discurso científico, o autor admite que a migração conceitual refere-se a um deslocamento, ou seja, uma apropriação temporária, não necessariamente uma fixação e que o conhecimento ocorre, também, na atmosfera de tais migrações. Alerta, entretanto, que a estabilidade de um conceito verifica-se, justamente, pelo que mais se teme, ou seja, a não-resistência a reformulações e, até mesmo, por meio de apropriações por outros campos do conhecimento, acabando por revitalizar conceitos já extintos.

Este estudo voltou-se à noção de conceito situada na literatura periódica em $\mathrm{Cl}$ no Brasil. Problematiza-se por que a noção de conceito, discutida amplamente em relação às suas origens filosóficas, às suas relações com as ciências e com a realidade, não tem sido suficientemente explorada no que se refere à riqueza e às conotações que adquire historicamente, à ideologia ou às relações de força existentes nos campos semânticos em que é representado e definido o conceito.

Vale ressaltar que a noção de campo semântico como conjunto estruturado de unidades lexicais, expressões lexicalizadas ou outras unidades linguísticas unidas por traços comuns em torno de um conceito-chave, é lócus propício às determinações de poder. Recorre-se, por analogia, a Bourdieu para esclarecer a noção de campo como um universo complexo de relações objetivas de interdependência entre sub-campos ao mesmo tempo autônomos e unidos pela solidariedade orgânica. Diz respeito a uma população, ou seja, um conjunto de agentes suscetíveis de serem submetidos a regras e unidos por interações observáveis direta ou indiretamente (1989, p. 373). Entretanto, não se deve identificar campo semântico com campo associativo ou conceitual, principalmente porque este não tem por objetivo ser exaustivo de modo a abranger todas as relações linguísticas de um vocabulário.

A "teoria dos campos semânticos", desenvolvida pelo linguísta alemão Jost Trier a partir da década de 1930, realça a noção de motivação na organização linguística centrada na individualidade de cada grupo cultural (AFONSO, 2000). Em íntima relação com as principais concepções contemporâneas referentes ao sistema linguístico, referese a um conjunto de unidades cujo valor depende apenas das suas interrelações. Segundo o autor, a teoria oferece um método para abordar um difícil problema, mas de crucial importância, a influência da linguagem no pensamento. Isso porque um campo 
semântico não reflete apenas as ideias, os valores e as perspectivas da sociedade contemporânea, mas as cristaliza e as perpetua, transmitindo às gerações seguintes uma análise já elaborada da experiência pela qual será visto o mundo, até que a representação se torne tão inadequada e antiquada que todo o campo tenha de ser refeito.

Desse modo, o conceito não pode ser considerado essência esclerosada e tampouco definitiva, pois só conserva seu status científico quando do esforço de análise e estruturação dos fatos, tornando-se estratégico por ser concebido a partir de uma operação de abstração dos elementos fortuitos ou das propriedades contingentes. Contém, entretanto, a riqueza do empírico e, no contexto de uma prática, é sempre posto a prova e revisto periodicamente. Coadjuvante desta fundamentação, a conceitualização é o processo de constituição de um sistema de termos significativos. Nesse caso, os instrumentos criados pelas linguagens naturais ou artificiais trabalham com conceitos, para representá-los de maneira rigorosa e não equívoca. Portanto, a definição clara dos conceitos empregados em qualquer área e atividade do conhecimento visa um melhor entendimento da realidade, intensificando a tendência ao genérico-categorial. Essa abstração é que possibilita, como argumenta Lukács (2010, p. 297), a síntese dos sinais "surgidos de objetos e processos, como complexos enunciativos unitários, elevando assim os sinais singulares do nível aproximativo de 'representações' para aquele da aproximação ao conceito."

Defende-se, portanto, o contexto histórico como determinante constitutivo do conceito, pois este não é instituído sem a participação do sujeito em sua historicidade, em determinada cultura e condições específicas. Ao sujeito, favorecido pelos elementos vivos que refletem e refratam a realidade que os produziu, é atribuído o poder de abstrair para criar e intervir.

A partir dessa percepção, foram levantadas na literatura artigos sobre "o conceito", sua concepção e evolução, como objeto de estudo na área de $\mathrm{Cl}$. O corpus de pesquisa constituiu-se de 75 artigos (Apêndice), selecionados da Base Referencial de Artigos de Periódicos em Ciência da Informação (Brapci), entre os anos de 1975 e 2011, a partir dos quais se procedeu a análise de conteúdo. Levaram-se em conta a concepção dos autores e seus fundamentos teóricos para a identificação das categorias temáticas mapeadas na figura 1, relacionadas com a concepção e evolução do conceito, como objeto de estudo. 
Segundo a concepção hegemônica entre os autores que fundamentam esta pesquisa, os conceitos são sínteses de enunciados considerados verdadeiros sobre objetos do pensamento. Esses enunciados ou asserções levam ao reconhecimento ou à separação das características dos conceitos que, segundo Dahlberg (1978a), também podem ser consideradas como seus elementos. Assim, para a autora, o conhecimento se fixa pela linguagem, em relação direta e interdependente. Desse modo, novos conhecimentos aparecem com novos elementos linguísticos e também por meio destes tornam-se mais claros e precisos. A autora define o conceito como uma unidade de conhecimento surgida da síntese dos predicados necessários relacionados com determinado objeto e que, por meio de sinais linguísticos, pode ser comunicado.

A evolução da ideia do conceito acontece paralelamente às discussões sobre a teoria do conhecimento, especialmente entre duas concepções opostas, o racionalismo e o empirismo. O intelectualismo, considerado um modo de superação para que se compreenda a formação do conhecimento, propõe, além das representações intuitivas sensíveis, "os conceitos, que enquanto conteúdos não-intuitivos da consciência são essencialmente distintos das representações sensíveis, embora mantenham com elas uma relação genética, na medida em que são obtidos pela experiência. Deste modo, experiência e pensamento constituem, em conjunto, o fundamento do conhecimento" (HESSEN, 2003, p. 60).

Ao focalizar o conceito no contexto de um vocabulário controlado, Dodebei (2002) define-o como um item que reflete o conhecimento "do mundo real dos objetos e dos fenômenos, com seus atributos e relacionamentos semânticos e acidentais". Nesse contexto, o conceito é uma unidade informacional que pode ser representada por apenas uma palavra ou por uma expressão, desde que essa expressão designe um único conceito. Desse modo, os conceitos são representações mentais das relações que ocorrem entre objetos na realidade empírica e, com base na definição de conceitos, foi desenvolvida a Teoria Geral da Terminologia (TGT), por Eugène Wüster, na década de 1930, para poder ser empregada na área de documentação.

Testemunhas que "muitas vezes falam mais alto que os documentos", as palavras e os termos ganham significados historicamente. Ao se referir a palavras como "indústria", "industrial", "classe média", "classe trabalhadora", "capitalismo" e "socialismo", Hobsbawm (1998) alerta que elas passaram a representar coisas e conceitos a partir da revolução 
que "eclodiu entre 1789 e 1848, e que constituiu a maior transformação da história humana, desde os tempos remotos [...]" (HOBSBAWM, 1998, p. 17).

Portanto, boa parte do pensamento criativo do qual depende esse tipo de transformação representa uma tentativa de reexaminar conceitos e práticas, na convicção de que "o sistema que os gera e deles se compõe" seria intolerável e não sobreviveria (WILLIAMS, 2011, p. 407). Este pensamento inclui propostas de novas formas de processos decisórios, de educação, definições e práticas de trabalho, tipos de comunidades e de utilização da terra. Desse modo, o autor desmistifica conceitos consagrados numa acepção literária e histórica, revelando como certos termos definem distinções sociais, como ilustram os exemplos da estrutura econômica da sociedade rural. Alguns textos referem-se à atividade de 'lavrar' e 'pastorear' do proprietário, enquanto os trabalhadores "trabalham". Da mesma forma, o empreiteiro e o arquiteto "constroem", enquanto os operários "trabalham" em uma obra, um senso comum que atravessou o tempo.

Os conceitos, desse modo, se forjam no cotidiano e são realidades em constante transformação, alimentadas ou suprimidas em contexto dinâmico de produção e troca. Consequentemente, assim como os conceitos, os termos que os representam são forjados, suprimidos ou eliminados, pois como uma realidade em permanente vir a ser, a linguagem segue a evolução da vida social. A percepção de que conceitos consagrados levam a incompreensões no processo de análise e organização do conhecimento, indica que o "leitor", indexador ou organizador do material de algum modo expresso, deva compreender a "leitura" ao realizar uma análise conceitual. Mesmo assim, nunca se poderá ter a certeza de que o resultado represente, adequadamente, o conteúdo de um documento para que ocorra a "correspondência com o assunto pesquisado pelo usuário" (FUJITA; RUBI, 2002). Para que essa correspondência aconteça, a adoção de uma postura dialógica em relação ao contexto e à conjuntura torna-se imprescindível, pois ela será norteadora de princípios e critérios que servirão de guia na tomada de decisões para o aperfeiçoamento dos serviços e a racionalização dos processos.

O universo temático dessa exposição sintética auxiliou a composição de uma problemática que desafia a entrada na seara do conceito como objeto de pesquisa. Isso significa entrar na relação dialógica entre os aspectos de interdependência dos conceitos, tanto em relação aos termos, quanto em relação à realidade empírica. Se, por um lado, "não reconhecer que a ideia precede a palavra é tão impossível quanto não reconhecer 
que a criança existe antes de ter um nome [...]" (WHITNEY, 2010, p. 136), por outro, o termo não pode ser considerado como elemento isolado, pois, ao representar conceitos torna-se um enunciado, elemento vivo e real que compõe os discursos. Nessa composição, o termo passa a ter o valor de elemento comunicativo e ideológico, distinguindo-se das formas neutras da língua, portanto, inseparável do conceito. É por meio da palavra que o sujeito se define em relação ao outro, isto é, em última análise, em relação à coletividade (BAKHTIN/VOLOCHINOV, 2004, p. 113). Da mesma forma, o trabalho de analisar conteúdos para representá-los passa a significar um convívio com a alternância dos sujeitos e do contexto em que se representam os conceitos no cotidiano social. Essa alternância foi observada no interior de um corpus de 75 textos neste estudo analisados, inicialmente numa recuperação diacrônica, para, num segundo momento, se organizar tematicamente uma representação gráfica da síntese pretendida.

\section{O ESTUDO SOBRE O CONCEITO NA LITERATURA PERIÓDICA EM CIÊNCIA DA INFORMAÇÃO NO BRASIL: ANÁLISE DO CORPUS}

A busca na literatura sobre organização do conhecimento, sob um enfoque diacrônico, resultou no encontro com as remotas preocupações relacionadas ao conceito, a partir do ano de 1975. Críticas aos sistemas de classificação e inadequação nas formas de representação, devido principalmente à complexidade dos conceitos, são acompanhadas de modos de compreensão das relações entre eles. Para facilitar o entendimento dos estudos sobre o conceito, propõe-se um esquema de "organização de conceitos", ao invés de uma classificação, o que, segundo Datta (1977), pode ser valiosa modalidade de recuperação da informação.

Observa-se que, até o final da década de 1990, raras pesquisas sobre a fundamentação teórica e epistemológica relacionada aos conceitos, predominando os estudos normativos ou aplicados a situações concretas na construção de vocabulários controlados e tesauros.

Somente após o ano de 2000 surgem as primeiras concepções teóricas sobre ontologias e consequentemente os estudos de taxonomias e de fundamentos linguísticos. Essa intensificação deve-se provavelmente ao fato de que, na IV edição do Encontro Nacional de Pesquisa em Ciência da Informação (Enancib), promovido pela Associação Nacional de Pesquisa e Pós-Graduação em Ciência da Informação (Ancib), ocorrido em Brasília, foi criado o Grupo de Trabalho Epistemologia da Ciência da Informação, hoje 
Estudos Históricos e Epistemológicos da Ciência da Informação. Amplia-se então a percepção do conceito, antes voltada prioritariamente ao empírico.

$\mathrm{Na}$ Tabela 1 observa-se como a evolução se distribui tematicamente desdobrando-se o estudo do conceito em relação aos domínios da Terminologia, Linguística, Taxonomia e Classificação, Folksonomia, Ontologia, Modelo conceitual, Representação e Teoria do Conceito, Processo do Saber (Conhecer), Indexação, Vocabulário Controlado, Tesauros, Áreas de Domínio, Mapas Mentais e Conceituais.

Tabela 1 - O objeto "conceito" e seus relacionamentos temáticos

\begin{tabular}{lcc}
\hline Relacionamentos temáticos & Total & $\%$ \\
\hline Terminologia & 9 & $12,0 \%$ \\
Linguistica & 3 & $4,0 \%$ \\
Taxonomia e Classificação & 7 & $9,33 \%$ \\
Folsksonomia & 5 & $6,67 \%$ \\
Ontologia & 13 & $17,33 \%$ \\
Modelo Conceitual & 1 & $1,33 \%$ \\
Teoria do Conceito e Representação & 13 & $17,33 \%$ \\
Processo do saber (conhecer) & 1 & $1,33 \%$ \\
Indexação & 8 & $10,67 \%$ \\
Tesauros & 5 & $6,67 \%$ \\
Áreas de domínio & 3 & $4,0 \%$ \\
Mapas Mentais e Conceituais & 7 & $9,33 \%$ \\
\hline
\end{tabular}

Fonte: a pesquisa na Brapci

Os resultados obtidos com a análise e categorização do conteúdo permitiram a construção da Figura 1, cuja estrutura foi utilizada para tornar mais claros os enfoques relativos ao objeto da pesquisa. As categorias foram construídas a posteriori, com base na análise do conteúdo dos artigos recuperados na Brapci e a representação das temáticas constituiu três vertentes: a primeira, relativa aos estudos epistemológicos; a segunda apresentando os fundamentos teóricos da representação da realidade e a último, relacionada às aplicações empíricas que os estudos descrevem.

Figura 1 - Representação das temáticas relacionadas ao conceito 


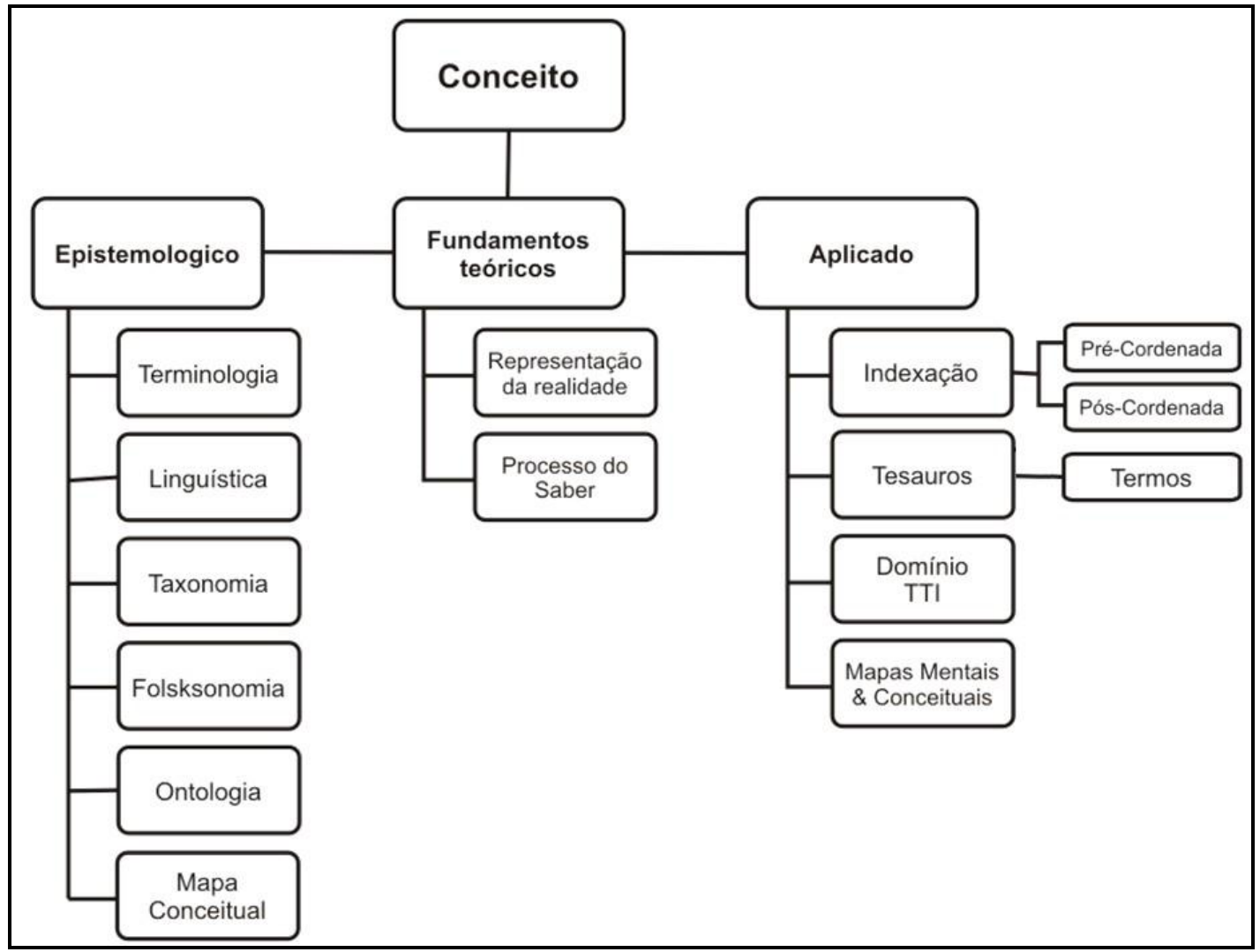

\section{Terminologia}

A primeira categoria identificada no esquema refere-se à terminologia, área de estudo dotada de instrumental teórico e metodológico para auxiliar das práticas de organização, representação e recuperação da informação. Com a terceira maior incidência em relação ao objeto deste estudo, seu destaque justifica-se pela sua concretude em representar o real nos conceitos (ideais).

A própria terminologia é destacada por Dias (2000) pela sua natureza interdisciplinar e suas aplicações práticas na era da informação. A autora faz uma análise da perspectiva poliédrica da terminologia como um objeto, uma prática ou uma disciplina, comparando diferentes pontos de vista.

Os processos de análise documentária e de construção de linguagens documentárias são explorados por Lara (2001), ao analisar o texto Marco Polo e o unicórnio, de Umberto Eco. A autora discute as semelhanças e diferenças entre os dois processos, definindo o conceito como a unidade de conhecimento criada pela combinação de características únicas e seus agrupamentos em função de propriedades comuns, já que nunca se esgotam as propriedades das coisas e fenômenos e a noção de conteúdo se relaciona. A construção desses vínculos apóia-se em referências concretas fornecidas 
pela terminologia do domínio e pelas referências de uso, que combinadas, permitem viabilizar a interpretação e a apropriação das informações documentárias.

O uso da terminologia teórica e da terminologia concreta é analisado em outro estudo de Lara (2004), instigando a ideia de que a linguagem documentária seja formulada rigorosamente e se constitua em sistema de organização e de comunicação da informação, qualquer que seja seu universo (bases bibliográficas, sites na WEB, conteúdos de manuais técnicos). Neste trabalho a autora fornece princípios para a identificação dos domínios, delimitação de conceitos e termos, estabelecimento de relações entre conceitos com apoio nas definições e no contexto dos descritores.

Ao discutir as implicações e limites teórico-metodológicas do conceito e da univocidade empregada na Análise Documentária (AD), Nunes (2002) propõe em seu trabalho a substituição pelo conceito de plurivocidade por considerar mais apropriado para lidar com as múltiplas dimensões do conhecimento.

A terminologia busca determinar o termo que denota um conceito específico e segundo Moreira (2005) a definição exata desta relação termo-conceito é fundamental para que se possa organizar e comunicar informações. Aplicável, em diversas áreas de estudo, dentre elas a Ciência da Computação (CC), a terminologia é descrita em seus principais aspectos e é discutida sua aplicação na modelagem de sistemas computacionais, uma vez que oferece uma base sólida para a construção de um sistema de conceitos.

Pereira e Bufrem (2005) analisam os princípios e métodos de organização e representação de conceitos para as Linguagens Documentárias (LD), enfocando principalmente a Teoria da Classificação Facetada (Ranganathan), a Teoria Geral da Terminologia (Wüester) e a Teoria do Conceito (Dahlberg). Consideram que um conceito pode ser definido, seja em relação aos dados empíricos ou pelos aportes teóricos que o constituem. Propõem uma síntese de princípios/características para a $A D$, que comporta em si dois sentidos: o de método interpretativo e o de teoria, cujo conhecimento é produzido a partir do método.

A interface entre Linguística, Documentação e Terminologia é analisada por Tálamo e Lara (2009), com ênfase nos procedimentos pedagógicos da educação e formação do documentalista. As autoras destacam a dificuldade em harmonizar um objeto plural ou poliédrico, como é o caso do termo, em conceito unitário. Ressaltam a 
superioridade da linguagem natural e discutem a proposta de LD em diálogo com a Terminologia.

Considerada por Gomes, Campos e Guimarães (2010) como uma área de estudo com ferramental teórico e metodológico de auxílio às práticas informacionais, a terminologia, é enfocada sob o ponto de vista onomasiológico, em que o conceito é o ponto de partida e semasiológico, que parte das palavras e de seus diversos significados. Os autores consideram que ambas as abordagens são de fundamental importância e podem mesmo ser consideradas complementares.

O campo da organização dos saberes é analisado por Saldanha (2010) a partir da filosofia da linguagem, problematizando a virada linguística e sua importância informacional. O autor critica a terminologia adotada para classificar o campo que atua com preservação, representação e transmissão de conceitos e artefatos que possibilitam a construção coletiva do conhecimento. Categoriza a tradição representacionista e a tradição pragmática, descrevendo o legado epistemológico do campo informacional por meio das manifestações institucionais que atravessaram o século XX.

Do exposto, percebe-se que os estudos no campo terminológico se fazem acompanhar, tanto pela reflexão teórica sobre seus fundamentos, quanto pela descrição e crítica de procedimentos terminológicos empíricos.

\section{Linguística}

A linguagem e sua aplicação na representação dos conceitos é outra vertente de estudos explorada pelos pesquisadores. Foram identificados três trabalhos relacionados com o objeto deste estudo.

A temática da linguística e da CI na atualidade reúne, segundo Mendonça (2000), alguns dos principais problemas do campo da informação. O autor ressalta que a linguística é utilizada para a construção de conceitos no campo do conhecimento humano, enquanto a $\mathrm{Cl}$ é responsável pelo tratamento e transmissão deste conhecimento. Partindo de uma pesquisa em artigos de periódicos científicos da área, a autora destaca sete pontos em que ocorre a interseção entre linguística e $\mathrm{Cl}$ : o teórico; o quantitativo, pela visão bibliométrica; o temático, pela representação da informação; o aplicativo, pelos métodos diversos; o ensino, pelas relações curriculares; o tecnológico, pela teoria de sistemas e o normativo, pelas classificações bibliográficas. Os artigos do subgrupo 
voltado à estruturação e a representação do conhecimento por meio de elementos da linguagem e da psicologia cognitiva enfocam, segundo a autora, o conceito visto pelo prisma do conhecimento e recuperação da informação.

Considerando que qualquer prática informacional tem uma estruturação que viabiliza a transferência da informação e a sua efetivação enquanto conhecimento, Azevedo Netto (2008) argumenta que essa efetivação se realiza a partir da estruturação e uso de conceitos. Considerando que essa estruturação se dá no nível discursivo de cada comunidade informacional, o autor utiliza a noção de discurso fundada em Foucault, os aportes teóricos de Dalhberg, para a teoria do conceito e, de Cassirer, para a discussão da representação. Assim, a conceituação e compartilhamento das representações sociais fazem com que seja necessário o entendimento do papel dos conceitos dentro da formação simbólica e discursiva em uma comunidade. Para tanto, discute a formação e prática do discurso, sob o ponto de vista da teoria semiótica de Peirce (1977) e propõe a análise da entidade conceito como estrutura semiótica.

A leitura sobre a evolução das LD na Documentação e seu campo de estudo, a Linguística Documentária, é explorada por Vogel (2009), tendo como foco a apropriação da noção de estrutura da Linguística Estrutural pela Documentação. A autora apóia-se nas pesquisas desenvolvidas pela linha francesa na Europa, notadamente por JeanClaude Gardin e, no Brasil, pelo Grupo Temma.

Percebem-se, nos três trabalhos voltados à Linguística, reflexões de caráter teórico sobre as questões relacionadas ao conceito, sua construção, estruturação e uso.

\section{Taxonomia}

Taxonomia, por definição classificação sistemática, é conceituada por Campos e Gomes (2008) no âmbito da Cl como ferramenta de organização intelectual. Empregada em portais institucionais e bibliotecas digitais como um novo mecanismo de consulta, ao lado de ferramentas de busca, a taxonomia é também um dos componentes na construção de Ontologias. A organização das informações por meio do conceito de Taxonomia permite em um sistema de informação, trabalhar de maneira lógica e por meio de navegação. O estudo dos autores apresenta o método de categorização bem como os princípios e cânones para elaboração de taxonomias como meio de representação e de acesso. 
A Classificação ou taxonomia, para Nunes e Tálamo (2009), é uma função importante para a funcionalidade dos sistemas de informação, pois possibilita seu compartilhamento e reconhecimento como matricial, quando outras funções advêm dela. As autoras criticam os sistemas de classificação bibliográfica existentes por não suportarem o volume informacional, o que para elas compromete a recuperação da informação, e justifica o estudo de novos métodos de tratamento da informação que tornem viáveis as respostas das organizações de documentos. Elas ressaltam que o planejamento prévio dos procedimentos deva reconhecer no usuário o alvo principal do sistema e que, portanto, as classificações bibliográficas devem responder às suas necessidades. Além disso, os sistemas de classificação necessitam aprofundar a teoria dos conceitos e das categorias para auxiliar a representação do conhecimento, assim como devem considerar o aumento dos acervos e das informações digitais como a realidade exige.

Partindo da observação da diversidade de conteúdo das definições do termo taxonomia, localizadas em variadas fontes, Aganette, Alvarenga e Souza (2010) constatam que o conceito de taxonomia vem sendo usado em diversos domínios científicos e tecnológicos, dentre esses a $\mathrm{Cl}$. Buscam o entendimento semântico do termo taxonomia em algumas áreas do conhecimento que a utilizam, além da sua compreensão enquanto ferramenta de classificação e recuperação de informação na $\mathrm{Cl}$. Diversas definições foram analisadas e o resultado é apresentado de forma sintetizada, seguido de uma discussão sobre os enunciados verdadeiros sobre taxonomias.

A tentativa humana de estabelecer classes ou categorias mais do que uma ação supostamente de controle, é uma das formas mais hábeis de se representar uma realidade, trazendo subjacente o intuito de transformá-la em conhecimento. Com esse pressuposto, Siqueira (2010) apresenta um breve histórico sobre o estudo da classificação na humanidade e discute o conceito a partir das perspectivas de Foucault, Mauss, Lévi-Strauss e Piaget. Destaca o caráter pluridiverso do termo, e sua relevante aplicabilidade no contexto pós-moderno.

Em outro estudo do mesmo ano, Novo (2010) define o conceito de taxonomia como o conjunto de estruturas classificatórias para organização de um domínio de conhecimento e tem por finalidade permitir agregação de informação e dados, possibilitando acesso por meio de navegação. $\mathrm{Na}$ taxonomia de domínios interdisciplinares existe uma alta complexidade conceitual, pelo que é necessária uma 
base teórica própria. Neste sentido, sua construção, deve estar apoiada em uma teoria que viabilize princípios teóricos e metodológicos. O estudo apresenta o método empregado na estruturação da taxonomia da Geoquímica Ambiental e demonstra as etapas para modelização de domínios, baseadas na Teoria da Classificação Facetada e nos princípios da Teoria dos Níveis Integrativos.

Apresentando um estudo sobre a classificação facetada no âmbito das estruturas semânticas, Duarte (2010) define a taxonomia como um tipo de classificação capaz de identificar características comuns a diversas categorias de um assunto, organizando-o em partes denominadas de facetas. Envolve dois processos diferenciados, porém complementares: a análise de assunto em facetas e a síntese dos elementos constituintes. A autora concluiu que os princípios da teoria de Ranganathan são, portanto, aplicáveis a qualquer área do conhecimento.

Os estudos sobre o tema ressaltam que, enquanto o conjunto de estruturas classificatórias para organização de um domínio, a taxionomia ainda se realiza de modo incipiente e necessita de maior aprofundamento teórico para sua aplicabilidade empírica.

\section{Folksonomia}

A busca de critérios conceituais e metodológicos para a sistematização de linguagens de interface na organização e recuperação de conteúdos em plataformas virtuais interativas é analisada por Gracioso (2010). Movimento desprovido de métodos universais a priori, a folksonomia se estabeleceu no cenário colaborativo da Web procurando indexar os conteúdos interativamente e dinamicamente pelos usuários da rede. Sob outra perspectiva existe, em ambientes sistematizados da informação, a validação e aplicação de vocabulários controlados como instrumentos de recuperação da informação. No entroncamento destes dois caminhos a autora inicia a discussão sobre uma proposta metodológica para construção de instrumento de recuperação da informação que considere na sua estrutura a linguagem cotidiana, a linguagem de busca (e ação) da informação que difere do conceito de linguagem natural enquanto linguagem que compõe textos. Um estudo experimental foi conduzido como produto informacional para análise das condições sobre a proposta de uma linguagem de indexação aberta.

Diante da discussão sobre nomenclaturas dadas à indexação orientada pelo usuário em ambientes virtuais, Guedes e Dias (2010) situam o conceito "indexação social" no campo do tratamento da informação, baseando-se nas diferentes tipologias de 
linguagens e orientações de indexação. A partir da literatura especializada e de observações no ambiente da World Wide Web (Web), procuram contribuir para a discussão e o entendimento desta modalidade de indexação.

Ao discutir as potencialidades das folksonomias, Strehl (2011) parte da proposição e análise de esquemas de representação de conceitos que constituem os diferentes recursos de indexação de assuntos. Acompanha o desenvolvimento das fontes de informação especializadas e revisa os fundamentos técnicos da linguagem natural e documentária. Trata dos sistemas de recuperação que exploram as redes de colaboração inerentes à produção e ao uso da informação, ilustrando o funcionamento desse tipo de recursos ao tratar dos índices de citação e dos favoritos socializados. Distingue também o papel das folksonomias como instrumentos de representação conceitual e como pontos de acesso.

A recuperação da informação tem sido estudada dentro da $\mathrm{Cl}$, gerando e incentivando estudos para aperfeiçoar os resultados em buscas tanto na Web como em outros ambientes digitais informacionais. Santarem-Segundo e Vidotti (2011) analisam a Representação Iterativa, modelo sugerido para repositórios digitais, como um diferencial que altera o paradigma do auto-arquivamento de objetos digitais criando um conceito de relacionamento entre os termos que ligam o pensamento do usuário ao material depositado no ambiente digital. As ligações efetivadas pela Representação Iterativa com auxílio da Folksonomia Assistida geram uma estrutura em formato de redes que conecta de forma vertical e horizontal os objetos depositados, apoiando-se em algum tipo de estrutura de representação do conhecimento das áreas de especialidades e portanto criando uma rede dinâmica de tags baseada no conhecimento dos usuários.

Catarino e Baptista (2007) apresentam o conceito para a organização dos recursos digitais na Web, denominada de folksonomia, termo que surgiu no contexto da Web 2.0, do qual emergem novas formas de organizar e compartilhar os conteúdos disponíveis na Internet. Os autores destacam que a folksonomia é resultado de uma indexação livre do próprio usuário do recurso, e objetiva a recuperação a posteriori da informação, desenvolvida num ambiente aberto que possibilita o compartilhamento e, mesmo, em alguns casos, a sua construção conjunta. Com base na literatura, o trabalho descreve os diversos usos do termo folksonomia bem como outros conceitos a ele relacionados. Descreve também alguns serviços da Web que a adotam e menciona algumas vantagens e desvantagens na adoção deste tipo de indexação colaborativa. 
Discutida mais pelas suas potencialidades do que propriamente pelas concretizações, as folksonomias são analisadas sob distintos vieses e de modo predominante nos dois últimos anos.

\section{Ontologias}

As ontologias seguem uma linha teórica e prática que se destaca com prioridade nas preocupações dos autores em relacionar à construção de redes semânticas, a partir de bases de conhecimento e vocabulários controlados. Tem grande potencial para instrumentalizar a recuperação de informação vinculada a processos de cognição e de decisão.

Aceitando o pressuposto de que o conceito se constitui no componente invariável do processo de organização de bibliotecas tradicionais e digitais, Alvarenga (2001) fundamenta-se em três enfoques: o da teoria do conceito, sob a ótica da $\mathrm{Cl}$ e suas relações com os metadados, as ontologias e o processo de classificação; o segundo, relativo às peculiaridades e restrições intervenientes no processo de organização e tratamento da informação; e o terceiro, aos fatores específicos inerentes à representação e recuperação de informações. A autora ressalta as potencialidades dos recursos tecnológicos na criação de bibliotecas digitais e adverte que as atuais tentativas de classificação automática de documentos repetem experiências de muitas décadas, alcançando resultados ainda bastante limitados. A autora conclui que para superar o problema do registro e análise conceituais, seria necessária a criação de uma nova linguagem entendida por máquinas e seres humanos e capaz de codificar conceitos discursivos, gráficos e sonoros. Argumenta que o tratamento da web, tal como proposto por alguns sistemas de metadados, torna-se factível, desde que processado em nível da produção do documento primário, na construção de hipertextos, ou seja, aprioristicamente.

A relação dos fenômenos da informação e da cognição é analisada por Biolchini (2001), em referência às fundações paradigmáticas e às bases de conhecimento da área médica. O autor identifica a ausência ou escassez da utilização de relações semânticas nessas bases, como instrumentos de tratamento informacional, desenvolvidas no nível dos conceitos associados aos termos, assim como nas relações conceituais. Isso determina, para o autor, importante redução no grau de precisão do processo de recuperação informacional, pois não se considera a relevância clínica dos termos 
empregados na busca e tampouco as necessidades dos profissionais em sistemas com estas características. A construção de redes semânticas e ontologias, a partir de bases de conhecimento e vocabulário controlado são apontadas como uma linha de desenvolvimento capaz de fornecer os instrumentos necessários para aumentar a recuperação de informação relevante diante da diversidade do uso profissional da informação.

Moreira, Alvarenga e Oliveira (2004) destacam a demanda para desenvolvimento de sistemas que trabalhem com recuperação e troca de informação ou conhecimento. Os autores questionam a definição de ontologia e tesauros, buscando fundamentação para testar duas hipóteses: a primeira de que tesauros e ontologias seriam sinônimos e a segunda de que essa relação não é verdadeira, tratando de um equívoco terminológico. Os autores buscam argumentos nos autores da área de $\mathrm{Cl}$ para estimular a comprovação do estudo.

Em outro trabalho, Schiessl (2007) destaca a discussão do conceito de Ontologia, apontando problemas que motivam os pesquisadores da área em suas investigações. Contextualiza a sobrecarga informacional em virtude do crescente volume de texto eletrônico armazenado em bases de dados, em especial na Web, e sua implicação na manutenção do fluxo da informação. Introduz a idéia da Web Semântica como uma solução para a organização dos conteúdos das páginas da Web e o papel preponderante das ontologias, dentro deste contexto.

Sales e Café (2008) relatam pesquisa desenvolvida cujo objetivo consistiu em estudar as semelhanças e diferenças entre tesauros e ontologias. Como modelos de representação do conhecimento que servem como instrumentos de controle terminológico, os tesauros e as ontologias auxiliam o processo de indexação e recuperação de informações por assunto. Foi empregado, no plano metodológico, o Método de Análise de Conteúdo de Bardin. No plano teórico, a pesquisa foi subsidiada pela Teoria Comunicativa da Terminologia (TCT) de Cabré. Os autores ponderam que a análise dos resultados e interpretações proporcionou significativas contribuições, visto que inúmeras características semelhantes e diferentes entre tesauros e ontologias foram identificadas e comentadas. A constatação de que ambos os modelos apresentam analogias no tocante aos termos, conceitos e objetivos permite um entendimento mais profundo desses instrumentos. 
O conceito de ontologias se desenvolveu historicamente acompanhando as diversas áreas do saber, as quais se organizaram em determinadas épocas do pensamento humano. Procurando analisar esse desenvolvimento, Mucheroni, Paiva e Lobbo Netto (2009) conceituam três sistemas de ontologias (Aristóteles, Jacob Lorhard e Leibniz-Wolff) e os relacionam com a evolução das ontologias e os conceitos da Web Semântica atuais. Os autores referem-se à síntese do pensamento sobre ontologia em comparação com as formulações propostas por Dahlberg, encontrada em Campos (2004). O estudo visa auxiliar a elaboração das ontologias com possibilidade de aplicação em determinadas áreas de domínio.

A aplicação de mecanismos de Recuperação Inteligente da Informação com o uso da Ontologia é apresentada por Fachin (2009) como recurso possível e concreto do encontro entre uma pergunta formulada, uma informação armazenada e o retorno ao usuário. Apresenta a ontologia como a representação de uma conceituação, de um conjunto de conceitos estudados, analisados e especificados sobre uma determinada área de domínio. Apresenta uma investigação no Portal de Periódicos da CAPES, com a expressão de busca "recuperação inteligente da informação e ontologia" no contexto da $\mathrm{Cl}$. O autor destaca a necessidade de implementação e atualização dos mecanismos de buscas em portais, diretórios e base de dados e futuros estudos.

Em pesquisa relacionando tesauros e ontologias, Sales e Café (2009) focam as diferenças existentes entre os dois modelos de representação, destacando que são modelos baseados no controle terminológico de domínios específicos. Empregando, no plano metodológico, o Método de Análise de Conteúdo e no plano teórico, a Teoria Comunicativa da Terminologia (TCT), os autores constatam que ambos os modelos apresentam diferenças no tocante aos termos, conceitos e objetivos o que permite um entendimento mais profundo desses instrumentos imprescindíveis à comunicação técnica e científica.

Em estudo sobre o desempenho dos usuários e suas redes sociais eletrônicas, Moura (2009) considera a estruturação de instrumentos de organização da informação. Argumenta que a digitalização das informações, a redução dos rituais sincrônicos e a produção da informação sob demanda provocaram mudanças radicais na disseminação da informação, a ponto de exigirem alterações nas metodologias de elaboração dos instrumentos verbais de representação da informação. Ao definir "ferramentas ontológicas", a autora destaca a importância do mapeamento das categorias mais gerais 
de áreas específicas por programas computacionais que envolvem a Inteligência Artificial, com vista a oferecer um instrumento dinâmico de produção, organização e disseminação de conhecimento. Para a autora, integram a categoria de instrumentos ontológicos as linguagens de indexação (verbais e simbólicas), as taxonomias, os mapas conceituais, as ontologias, os Sistemas de Classificação Distribuída (Distributed Classification SystemsDCSs) e mais contemporaneamente as folksonomias. Ao analisar o surgimento dos novos instrumentos de representação da informação em ambientes digitais, a autora indica os impactos decorrentes da interoperabilidade entre essas ferramentas ontológicas disponíveis na Web e as redes sociais ad hoc, sugerindo a incorporação das novas mediações informacionais no processo de construção de linguagens de indexação em ambientes digitais.

Mesmo com a evolução da área de recuperação de informação, os usuários ainda sentem incerteza, ansiedade, dificuldade em traduzir as suas dúvidas em sistemas pouco interativos, refletido em seu comportamento de busca. Baseando-se nessas questões, Beppler, Fonseca e Pacheco (2009) propõem um framework chamado Hermeneus para recuperação e busca de informação, recorrendo ao círculo hermenêutico para prover os princípios do framework e à ontologia para delinear os conceitos requeridos. Sua proposta é a intermediação com os usuários, que poderão desenvolver as suas idéias enquanto navegam na informação recuperada e nos conceitos que as representam. A proposta do framework é composta por quatro módulos, indexação, recuperação, inferência e apresentação, este último composto de três componentes interativos: navegador de ontologia, instâncias recuperadas e informação adicional.

Rautenberg, Todesco e Steil (2010) voltam-se ao estado da arte da aplicação de ontologias no domínio da convergência tecnológica dos Agentes Computacionais da Engenharia do Conhecimento e Instrumentos da Gestão do Conhecimento, domínio este caracterizado pela interdisciplinaridade e complementaridade. Prospectando cenários, os autores concluem que aplicar ontologias, como modelos de conhecimento, contribui para a comunicação, com a formalização de uma fonte para publicação, compartilhamento, referência e aplicação de conhecimento interdisciplinar.

Ao tratarem de dois tipos de modelos de representação do conhecimento, taxonomia e ontologia, Vital e Café (2011) objetivaram identificar seus elementos distintivos, já que, para os autores, muitas vezes são utilizados de forma equivocada, por falta de clareza conceitual. As taxonomias trabalham no sentido de organizar a 
informação e/ou conhecimento em relações hierárquicas entre os termos. Já as ontologias buscam estabelecer relações semânticas entre conceitos, em forma de redes conceituais, próximo da estrutura que trabalha o cérebro humano.

O contexto em que se produziu a revisão do conceito de tesauro como linguagem documental vem determinando, segundo Moreiro González (2011), pela revalorização das taxonomias, o aparecimento das Ontologias como Knowledge Organization System (KOS) e a evolução dos próprios tesauros para o seu enriquecimento conceitual e a sua transformação em redes semânticas. O autor refere-se também ao novo modelo de visualização e representação conceitual dos Topic maps, bem como à relevância atingida pelas folksonomias.

Percebe-se a tendência crescente dos estudos sobre as ontologias, categoria da maior incidência entre os artigos analisados, especialmente a partir da década de $2000 \mathrm{e}$ com especial ênfase no ano de 2009, o que indica a busca por novos modelos e representações relacionais de conceitos.

\section{Modelo Conceitual}

Adotando uma perspectiva interdisciplinar envolvendo as áreas da $\mathrm{Cl}$, da $\mathrm{CC}$ e da terminologia, Campos, Campos e Souza (2003) contribuem para a definição de critérios que venham a auxiliar a elaboração de metodologias para modelos conceituais, voltados não somente para sistemas de bases de dados, mas também para sistemas que visam à organização de unidades de conhecimento, como é o caso de hiperdocumentos.

\section{Teoria do Conceito e Representação da realidade}

Ao definir o conceito como a unidade de conhecimento que surge pela síntese dos predicados necessários relacionados com determinado objeto e que, por meio de sinais linguísticos, pode ser comunicado, Dahlberg (1978a) antecipa que na elaboração do saber a respeito de determinado objeto não são imprescindíveis todos os possíveis predicados com ele relacionados. Bastariam os chamados predicados necessários, na mais precisa forma linguística. Desse modo, a formação dos conceitos seria a síntese dos predicados necessários e verdadeiros a respeito de determinado objeto, sendo cada predicado relacionado a uma característica (elemento). A autora esclarece os tipos de relacionamento entre os conceitos e os termos, argumentando que a aplicação da teoria 
analítica dos conceitos na construção de sistemas mostrará seu valor na doutrina das definições e significados, apresentando um panorama da atividade internacional no setor.

Com o pressuposto de que as linguagens naturais possibilitam a formulação de enunciados a respeito de conceitos individuais e conceitos gerais, Dahlberg (1978b) considera ainda que todo enunciado sobre objetos contenha um elemento que se identifica como característica do respectivo conceito. Características idênticas evidenciam relações entre conceitos. A intenção de um conceito é a soma total de características e a extensão do conceito é a soma total de conceitos mais específicos. A categorização formal dos conceitos - objetos, fenômenos, processos, propriedades, relações - tem importância na formação de sistemas e na sua combinação. As definições corretas dos conceitos são suma importância para o contínuo desenvolvimento da Ciência, pois é pela linguagem que se conduz à utilização e criação de novos conceitos em um domínio, representado por seus termos, que segunda a autora não é fácil de manter.

Os conceitos são construções que devem ser interrogadas para que tornem visíveis as condições de possibilidade de sua emergência. A pesquisa de Costa (1996), partindo desse pressuposto, analisa o conceito de memória institucional, objeto da investigação que se volta para as diversas maneiras de trabalhar com a questão conceitual, entre as quais a representação e o acontecimento.

Para discutir alguns aspectos da formação e da representação de conceitos, Mari (1996) parte do estatuto que esta questão assumiu no desenvolvimento das teorias semânticas para as línguas naturais, nos últimos tempos. Em complemento a este enfoque conceitual, destaca a sua importância na compreensão de práticas com linguagens específicas. O autor busca diferenciar os conceitos de conhecer, representar e informar, assim como a forma de representação conceitual, ressaltando a produção do sentido na constituição de atos de fala.

Para Campos (1995) pouca atenção vem sendo dada à criação de novos instrumentos de recuperação da informação e do uso crítico dos mesmos, segundo. A autora levanta questões relacionadas à criação de um núcleo básico de conhecimento necessário às atividades de pesquisa, ensino e elaboração de linguagens documentárias, como o tesauro e a tabela de classificação. Argumenta que estudantes de escolas de biblioteconomia deveriam ser incentivados a participar de estudos em busca de elementos comuns para a formação de um sistema de conceitos e suas relações, tendo por base as teorias da terminologia, da classificação facetada e do conceito. 
Em estudo complementar, Campos (1996) realiza uma síntese do desenvolvimento das pesquisas na área de representação e recuperação da informação, visando à elaboração de sistemas de conceitos. A autora apresenta questões que envolvem o conceito/termo e as relações entre conceitos, enfatizando as abordagens que evidenciam os aspectos comuns entre a teoria da classificação facetada, a teoria do conceito e a teoria da terminologia, cujos princípios permitem a estruturação em um sistema dos conceitos.

A construção de conceitos, na concepção de Galvão (1998), interfere na ruptura epistemológica de uma ciência e no desenvolvimento de modelos científicos voltados para a observação, descrição e interpretação dos objetos teóricos e empíricos de um campo do conhecimento. Para o autor, o arcabouço da biblioteconomia e da documentação apresenta alguns problemas metodológicos, entre eles a construção de conceitos descritivos sem uma paralela preocupação com a elaboração de conceitos metodológicos correspondentes e a perspectiva eclética adotada em sua construção.

Ao analisarem a questão da representação do conhecimento a partir das dificuldades existentes no uso das classificações documentárias objetivando a recuperação e disseminação de informações, Moraes e Arcello (2000) realizam uma abordagem sobre as principais correntes filosóficas, organizando-as por períodos e extraem conceitos sobre a representação da realidade e as influências sofridas em sua elaboração.

Azevedo Netto (2002) explora o conceito de informação e permite o confronto e relação com conceitos de outras áreas ou disciplinas. Discute as correlações entre alguns aspectos e conceitos que se interpõem na questão da natureza do processo de comunicação, ao qual a informação está intimamente ligada, visando um melhor tratamento e delimitação desse objeto. Para tanto, toma como base a Teoria Semiótica de Peirce, em especial as noções de signo e sinal, e finalmente a relação entre estes dois e o conceito de informação.

As teorias e metodologias voltadas para a representação do conhecimento são estudadas por Campos (2004), tanto no escopo temático da $\mathrm{Cl}$ quanto no da CC, enfatizando os modelos de abstração utilizados pelas áreas, especialmente o modelo orientado a objetos da CC e as teorias ligadas a conceitos da Cl. 
O problema das semelhanças e diferenças entre a informação, o conhecimento e o valor é analisado por Rendón-Rójas (2005), que toma como elementos de análise suas fontes de origem, as atividades que se realizam para obtê-las e suas características específicas. O autor conclui que existem diferenças essenciais entre esses três fenômenos, e que eles não podem ser vistos como três etapas de um mesmo e único processo. A mesma conclusão é válida, segundo o autor, para diferenciar a sociedade da informação a sociedade do conhecimento e a sociedade do valor.

Os princípios de organização de conteúdos já estabelecidos no âmbito das Teorias da Classificação e do Conceito fornecem bases teóricas e metodológicas para o planejamento e elaboração de hiperdocumentos, segundo Campos e Gomes (2005). estudo das autoras demonstra a classificação facetada de Ranganathan na elaboração de um método de classes gerais ou facetas, no interior das quais se inserem as classes específicas e, de outro, em princípios para relacionar estas últimas. Objetivando o estudo da preparação de hiperdocumentos com fins didáticos em ensino à distância, as autoras concluem que a Teoria do Conceito complementa o Método de Faceta, ao contribuir para a organização interna do conteúdo de cada nó, pois neste sentido um nó é considerado um conceito. Desta forma, ao definir a abrangência de conteúdo a ser tratado em um nó conceitual deve-se primeiro esgotar todos os elementos que permitem o entendimento deste nó/conceito, ou seja: o que é o conceito e quais os seus elementos constitutivos.

A construção do conceito é analisada por Medeiros (2010) a partir das proposições de Michel Foucault, e de Ingetraut Dahlberg, para compreender as relações que as duas teorias podem apresentar e como elas podem ser utilizadas de forma complementar.

\section{Processo do saber}

No estágio atual da Cl, observa González de Gómez (1984), cresce o interesse pelo ponto de vista cognitivo acerca de processos e produtos informacionais. Teses e tecnologias de informação apresentam suas correspondentes premissas cognitivas, implícitas ou explícitas. Ao colocar o usuário da informação como o sujeito do conhecimento, baseado nas premissas cognitivas que transformam os processos do saber, a autora afirma que essa caracterização do sujeito tem consequências teóricas e práticas com respeito à informação, revisando alguns dos enfoques principais (formaluniversalista, psicologista, entre outros), e levanta a questão da importância das condições sócio-históricas do sujeito gerador-usuário de conhecimento e informação. 


\section{Indexação}

Dos estudos empíricos relacionados aos conceitos, destacam-se aqueles sobre indexação, principalmente sobre as questões concernentes à extração do melhor termo para representar um conceito. Carvalho e Carvalho (1975) discutem como a Semântica atingiu o estágio de desenvolvimento que passou a exigir uma classificação bibliográfica adequada para os documentos a ela dedicados. As autoras apontam como as dificuldades para a elaboração de um sistema de classificação se acentuam quando a ciência a ser focalizada é relativamente nova. Neste caso, as teorias, os conceitos, as leis e os métodos da nova ciência ainda não foram amadurecidos, e qualquer classificação permanecerá provisória até que pelo menos suas bases tenham sido definidas. Diversos conceitos são apresentados pelas autoras para se extraírem termos que poderiam constar em uma classificação. Elas salientam que os conceitos abarcam toda a realidade e que qualquer alteração nos limites de um conceito acarreta uma modificação nos conceitos vizinhos e consequentemente nos termos que os expressam.

Os princípios requeridos para uma classificação geral e métodos a serem aplicados em indexação pré-coordenada foram examinados com fundamento na evidência psicológica da natureza do conhecimento (DATTA, 1977). Fundamentado teoricamente nos trabalhos do Classification Research Group, de autores como J. Farradane, Foskett e Guilford, além de sua própria construção teórica, o autor apresenta um esquema a partir de uma divisão primária em tipos de conceitos básicos, a subdivisão destes em várias colunas paralelas, o arranjo de termos ou conceitos em cada coluna, em diferentes níveis de complexidade, a representação de classes genéricas em qualquer nível, e uma apresentação em separado de tipos mais complexos de conceitos ou termos que são heterogêneos em relação aos tipos de conceitos básicos. Segundo o autor, esse esquema que pode ser mais bem denominado "organização de conceitos", ao invés de classificação é particularmente valioso em recuperação da informação.

Voltadas ao processo de indexação, destacam-se as recomendações da UNISIST (United Nations International Scientific Information System) com o objetivo de estabelecer os princípios básicos do processo de indexação com o propósito de facilitar o intercâmbio entre sistemas de informação. Demonstrando as operações de indexação em seus diversos estágios. Para aferir a qualidade do processo de indexação, segundo o estudo deve-se realizar a avaliação das recuperações, desta forma definindo-se mudanças no processo sempre que necessário. (UNISIST, 1981). 
Em um estudo aplicado da lei de Bradford-Zipf, Robredo (1982) sugere seu uso na identificação de termos no processo de indexação. O autor estuda dois universos de termos significativos correspondentes a duas áreas diferentes do conhecimento (agricultura e política científica e tecnológica), resultantes da análise do conteúdo de conjuntos suficientemente grandes de documentos, indexados segundo princípios não subjetivos: indexação automática no primeiro caso e indexação automática simulada no segundo. Desse estudo resultam, para cada caso, listas de descritores estabelecidas a partir de suas respectivas frequências de aparecimento e da aplicação de determinados conceitos de sinonímia e quase-sinonímia, que devem contribuir para aperfeiçoar os processos de indexação e recuperação da informação, tanto em sistemas manuais como automatizados. As conclusões estabelecidas no que diz respeito à melhoria da indexação parecem confirmadas a partir dos conceitos da teoria da informação.

Cavalcanti (1982) analisa produtos documentários e a intervenção do classificador/indexador para a descoberta ou identificação do assunto, tema ou tópico do documento. Identifica os inovadores da indexação alfabética e apresenta o índice como elo de ligação entre o usuário e a informação, resultante de um processo de indexação cujos principais tipos são: associativa; automática; contextual; coordenadora; correlativa; de citações; de conceitos; derivada; em cadeia; hierárquica; na fonte; pela palavra-chave; por relações; por truncamento; pós-coordenada; pré-coordenada; por unitermos. O autor apresenta questões ligadas aos mecanismos, metodologias da indexação, a identificação e seleção de conceitos.

Ao definir indexação como a "operação que consiste em escrever e caracterizar um documento, com o auxílio da representação dos conceitos nela contidos", Chaumier (1988, p. 63) alerta para os ruídos e silêncios na busca informacional e analisa o processo de indexação em suas etapas: conhecimento do conteúdo do documento, escolha dos conceitos e tradução dos conceitos escolhidos em linguagem documentária e incorporação dos elementos sintáticos. Discute os sistemas de classificação e tesauros como instrumentos da indexação, que pode ser realizada por um indexador humano por um programa de computador, ou ainda por um uma combinação de ambos.

A AD, definida como o processo de extrair conceitos que traduzam a essência de um documento, é, segundo Naves (1996), uma das etapas mais importantes no processo de indexação. A autora identifica na literatura várias concepções dadas ao termo, tais como análise temática, análise documentária ou análise de conteúdo, podendo-se 
verificar certa confusão com relação ao seu real significado. Questões e dificuldades são apontadas e discutidas com relação ao termo, e sobre o conceito de atinência.

Em estudo de Fujita (2003), a identificação de conceitos realizada durante a leitura documentária, envolve esforço adicional de compreensão de texto. Por meio de revisão de literatura, a identificação de conceitos a partir da leitura documentária, da tematicidade e das concepções de análise de assunto, a autora considera que as concepções de análise orientadas ao conteúdo e à demanda são decisivas ao bom desempenho do indexador durante a leitura para a identificação de conceitos na medida em que se vinculam à busca pela tematicidade do texto.

Em outro trabalho complementar, Fujita (2004) argumenta que a leitura é o processo que permite a análise de assunto de textos, causando influência no resultado da indexação. Visa esclarecer as dificuldades de análise de assunto de textos e reunir subsídios para a elaboração de orientação à formação do indexador em leitura documentária, contribuindo para o aprimoramento de sua capacidade de leitura.

Esse conjunto de artigos concentra-se em questões relacionadas à indexação como processo e aos instrumentos dela resultantes, diversificando-se em áreas e aspectos predominantemente voltados à relação entre conceito e termo.

\section{Tesauros}

O uso de conceitos e terminologias relacionados com a Informação para Negócios e Informação Tecnológica é analisado por Jannuzzi (1997) na construção de vocabulários temáticos, analisando o uso dos conceitos/definições e terminologias abstraídos da literatura. Confronta-os em uma pesquisa de campo sobre os termos praticados no Brasil, junto a coordenadores e técnicos da Rede de Núcleos de Informação Tecnológica do PADCT, do Sistema SEBRAE de Informação, e especialistas da área informacional. Por fim, analisa o confronto e faz sugestões para a uniformização dos termos praticados pelo mercado informacional.

Uma análise da Norma Internacional de elaboração de Tesauros Monolíngues (ISO 2788) é apresentada por Gomes e Campos (2004) que focalizam os aspectos relativos ao termo de indexação como base para intercâmbio de informações, a partir de princípios da Teoria da Terminologia de Wüster e da Teoria do Conceito de Dahlberg. Para o autor o Tesauro assume papel fundamental nesta integração, viabilizando a interoperabilidade semântica de sistemas distribuídos heterogêneos. 
Em estudo temático, Rodrigues (2005) elabora uma estrutura de classificação com o objetivo de ajudar a construir um futuro tesauro que terá como universo temático a cultura amazônica paraense. Foram coletados termos culturais da narrativa Chove nos Campos de Cachoeira, de Dalcídio Jurandir para estruturação do tesauro. Partindo do princípio de que toda informação organizada tem uma expectativa de geração de novo conhecimento, acredita-se que a elaboração desse tesauro será muito útil para a preservação da memória cultural amazônica.

Campos e Gomes (2006) analisam historicamente o tesauro documentário como uma relação estruturada de termos constituídos, quase exclusivamente, de uma única palavra. Posteriormente evoluiu para algumas palavras compostas sem, no entanto, estabelecer bases para isso. A elaboração de um tesauro implica bases classificatórias e as categorias fundamentais permitem correto posicionamento dos conceitos nas classes e a organização de um domínio. A definição de cada conceito é o elemento que vai comprovar objetivamente tanto as relações hierárquicas como as partitivas e associativas com outros conceitos.

Mostafa e Cruz (2010) afirmam que nas linguagens documentárias como os tesauros é comum a identificação de relações hierárquicas entre os termos a partir da lógica aristotélica e que nas relações associativas, a literatura de linguagem documentária não apresenta referencial teórico capaz de explicar as associações. As autoras sugerem o empirismo inglês de David Hume como a referência adequada às relações associativas em linguagem documentária, revisando os conceitos do filósofo, especificamente os de Relações Naturais e de Relações Filosóficas, de modo a propor uma alternativa teórica para as novas e infinitas associações entre os termos provindos da prática dos mais diversos campos do conhecimento.

\section{Domínio}

A delimitação de um domínio para construção de conceitos vem ganhando interesse dos pesquisadores. As teorias e metodologias desenvolvidas, tanto no escopo temático da ciência da informação quanto no da ciência da computação, que estão voltadas para a representação do conhecimento, apresentam, segundo Campos (2004), de forma mais ou menos abrangente, discussões sobre princípios como contexto de conhecimento, natureza dos conceitos, relações entre conceitos e sistemas de conceito. No campo do quadro teórico, a autora investiga os modelos de abstração utilizados nas 
duas áreas, os modelos representacionais associados à modelagem de sistemas de banco de dados, mais especificamente o modelo orientado a objetos. Da ciência da informação, ela analisa teorias ligadas à representação de sistemas de conceitos, como a teoria da classificação facetada e a teoria do conceito. Da teoria da terminologia, utilizamse princípios estabelecidos para a determinação de conceitos e suas relações. Garantindo a especificidade de cada área, a comparação entre as teorias se dá, tendo em vista quatro pontos relacionados ao processo de modelização: o método de raciocínio; o objeto de representação; as relações entre os objetos e as formas de representação gráfica.

Considerando a Análise Documental (AD) - como uma das correntes teóricas do Tratamento Temático da Informação, Guimarães e Sales (2010) partem de uma análise teórica da literatura sobre a dimensão conceitual da área para, a seguir, cotejá-la com a realidade investigativa brasileira em termos de conceito e de relações interdisciplinares de análise documental. Os resultados revelam uma forte influência gardiniana na realidade brasileira, na medida em que os processos de análise documental adquirem especial ênfase. Os autores ressaltam ainda que, diante das análises realizadas, sente-se a necessidade da comunidade acadêmica de AD refletir sobre as influências teóricas que as norteiam e, como consequência, com a terminologia que é utilizada para expressar os conceitos da área.

A busca do rigor no uso de termos e conceitos no discurso científico implica discussões sobre legitimidade e limites de domínio. Um dos problemas, apontado por Francelin (2011), é o de que, em determinados momentos, na dinâmica da ciência, os conceitos transgridem naturalmente fronteiras epistemológicas, processo não isento de críticas. O autor apresenta o contexto de acontecimento dos debates sobre a legitimidade no uso de conceitos além de seus campos de fixação, entendendo que a imposição de barreiras e, ao mesmo tempo, a falta de rigor na apropriação de conceitos isola e fragiliza o discurso científico. Entretanto, admite que a migração conceitual refere-se a um deslocamento, ou seja, uma apropriação temporária, não necessariamente uma fixação e que o conhecimento ocorre, também, na atmosfera de tais migrações.

\section{Mapas mentais e conceituais}

Marques e Siqueira (1983) distanciam-se dos padrões classificatórios tradicionais, em prol de uma linguagem documental ajustada às exigências de sistemas multidisciplinares de informação, no caso particular, aqueles voltados para o planejamento 
sócio-econômico. Os autores propõem um modelo de concepção de Thesaurus em que, "a priori", se estabeleceu a natureza das ocorrências para nomeá-las convenientemente, e, em seguida classificá-las por conjuntos semânticos - gerais ou específicos. Apresentam as estruturas globais e operacionais do Thesaurus e regras básicas para delimitação das abrangências das categorias e filiação dos conceitos (descritores) às categorias, propondo um modelo conceitual - prático-teórico - de natureza geral, para uma aplicação específica, neste caso, os sistemas estaduais de informação para o planejamento do Nordeste.

Apresentando os conceitos e utilização de mapas conceituais e mentais, decorrentes da concepção de aprendizagem significativa, Belluzzo (2006) identifica-os como instrumentos de apoio à gestão da informação e da comunicação. Ressalta que são tecnologias voltadas à mediação do desenvolvimento das habilidades de acesso e uso da informação na sociedade contemporânea, enfatizando a questão da convergência entre os tradicionais meios de comunicação, as novas possibilidades digitais e a necessidade de condutas de gestão interdisciplinar voltadas a uma linguagem significativa para as pessoas, enquanto seres históricos. A autora defende que pessoas bem informadas empregam seus conhecimentos para tomar decisões em seu tempo e destinadas ao bem comum, situações que fazem parte das características da Information Literacy ou Competência em Informação.

Silva e Oliveira (2006) discutem a importância dos mapas conceituais como estratégia didática, nas aprendizagens realizadas em ambientes virtuais. Conceitua a interação, suas peculiaridades e desafios, buscando alguns conceitos em Piaget, Vygotsky, Primo e Cassol. Na analogia que criam - turmas e orquestras, didática e partituras musicais - a interação garante a harmonia do conjunto, a produtividade e a significância da aprendizagem, coletivamente construída. Apontam os mapas conceituais, criados por Novak e fundamentados na teoria de Ausubel, como opção metodológica, uma ferramenta gráfica utilizada para representação da estrutura conceitual de um determinado conhecimento. Formam uma estrutura que vai dos conceitos mais abrangentes até os menos inclusivos.

Apresentando considerações sobre a classificação facetada, Duarte e Cerqueira (2007) concentram-se no âmbito da modelagem conceitual, com foco na análise de faceta. A teoria defendida prevê o agrupamento de termos de um dado campo do conhecimento em facetas homogêneas e mutuamente exclusivas, derivadas de níveis 
superiores por uma característica singular de divisão, teoria esta desenvolvida por Ranganathan na década de 1930. Os autores utilizam essa teoria na representação do conteúdo intelectual em sistemas de modelagem conceitual.

A teoria da análise facetada serve também de base metodológica na construção de um modelo estruturado semanticamente para auxiliar a organização e representação do conhecimento humano em hipertextos, apresentado por Lima (2007a). A análise facetada foi utilizada para categorizar os termos indexados, estabelecendo a relação semântica de conceitos e as relações entre eles expressas nos links. Uma única unidade de informação, uma tese de doutorado sobre o tema da análise assunto (NAVES, 2000), foi utilizada para construir um modelo conceitual anteriormente à implementação tecnológica do seu protótipo. O estudo foi aplicado a um modelo semântico e criar um protótipo chamado Mapa Hipertextual (MHTX).

Complementando a pesquisa, Lima (2007b) aplica um modelo na construção e implementação de um protótipo semanticamente estruturado para auxiliar a organização e representação do conhecimento em hipertextos, com base em quatro referenciais: a Teoria da Análise Facetada (TAF), a Teoria dos Mapas Conceituais, a estrutura semântica de links hipertextuais e as normas técnicas da Associação Brasileira de Normas Técnicas (ABNT). O protótipo, denominado Modelo Hipertextual para Organização de Documentos (MHTX), é formado por um Mapa Conceitual (MC) e um Sumário Expandido (SE). O protótipo seria objeto de implementação da Biblioteca de Teses e Dissertações do Programa de Pós-Graduação da Escola de Ciência da Informação da UFMG (BTDECI UFMG).

O crescimento contínuo da quantidade de informação disponível em suporte eletrônico traz consigo problemas relacionados à modelagem conceitual de sistemas de hipertextos, o que compromete o processo de folheio em hiperdocumentos. $\mathrm{O}$ artigo de Nonato e Lima (2008) trata da modelagem conceitual de sistemas de hipertextos do ponto de vista das teorias de representação temática. Inclui a aplicabilidade da teoria do conceito no processo de determinação de links e identificação de nós hipertextuais.

\section{Considerações parciais sobre o corpus}

A riqueza temática representada pelo corpus expressa bem os movimentos de uma área em processo de crescimento e institucionalização como a $\mathrm{Cl}$, exatamente no que se refere ao pensamento e atuação de seu núcleo disciplinar. Desdobrando-se em 
disciplinas como a Terminologia, a Linguística, a Taxonomia e Classificação, a Folsksonomia, a Ontologia, os Modelos e mapas conceituais, a Teoria do Conceito e Representação, o Processo do saber (conhecer), a Indexação, o Vocabulário controlado, os Tesauros e as Áreas de domínio, percebe-se que há uma lógica no desenvolvimento temático, coincidente com o desdobramento das necessidades de melhor representar conceitos, das contribuições evidenciadas pelos usuários, e das contribuições da tecnologia.

Em uma análise diacrônica das temáticas estudadas, observam-se duas fases distintas do uso e estudo do "conceito". A primeira, até 2000, principalmente com a aplicação e construção de instrumentos que auxiliam processos técnicos de indexação e recuperação de informação como vocabulários controlados e tesauros. A segunda fase caracteriza-se pelo questionamento dos métodos e estudos teóricos na tentativa de novas metodologias para representar o conhecimento em ambientes interativos e com grande quantidade de informações, como a Internet.

\section{CONSIDERAÇÕES FINAIS}

A análise sobre a noção de conceito situada na literatura periódica em $\mathrm{Cl}$ no Brasil revela predominantemente a sua posição nos estudos sobre terminologia, entendida, tanto como a fundamentação teórica para explicar o relacionamento entre conceitos e termos especializados, quanto como prática ou conjunto de métodos e atividades voltados para essa relação, ou ainda, como produto dessa prática, representado pelo conjunto de termos, ou vocabulário, de uma especialidade.

Percebe-se a valorização da definição "correta" do conceito, dado o contínuo desenvolvimento do conhecimento e da linguagem que conduz à utilização de termos e conceitos cujo domínio nem sempre é fácil manter. Esse raciocínio denota a percepção da historicidade do conceito, como uma primeira sinalização para a compreensão de que, se por um lado, é percebida a riqueza desse processo de transformação de conceitos e da influência da realidade e dos eventos concretos nessa transformação, por outro, há uma tendência a travar esse processo na tentativa parmediana de representá-lo corretamente.

O conceito é discutido amplamente em relação às suas origens filosóficas, às suas relações com as ciências e com a realidade, mas ainda não tem sido suficientemente explorado no que se refere à riqueza e às conotações que adquire historicamente, assim como à ideologia ou às relações de força existentes nos campos semânticos em que é 
representado e definido. Tampouco as questões relativas ao problema da influência da linguagem na produção ou transformação dos conceitos representam uma tendência que se reconheça como em ascensão.

Em uma análise diacrônica, percebe-se a evolução das concepções sobre as relações entre conceitos e termos. Os relacionamentos de assuntos passaram a ser regidos por uma forma dinâmica de incorporação de novos conceitos, influenciando o modo de abordagem do conteúdo, que antes pretendia ser generalista, abordando todos os temas em uma única estrutura, sem que se respeitasse o tempo para seu amadurecimento e reconhecimento pela comunidade científica. Além disso, a representação do conceito vem evoluindo. A possibilidade de ser representado por termos polilexicais situa o conceito em contexto de múltiplos e mais complexos relacionamentos.

É no início da década de 2000, quando os primeiros trabalhos teóricos passam a questionar o modelo vigente, que se adota o modelo de plurivocidade, considerado mais adequado para lidar com as múltiplas dimensões do conhecimento. É quando se inicia o processo de estabelecimento de domínios para cada modelo conceitual, e se estuda a possibilidade de criar instrumentos dinâmicos de representação com a construção coletiva do conhecimento.

Estudos mais recentes reacendem a crítica à ideia de que os conceitos nunca se alteram, o que muda são os termos ou as formas de representá-los. Percebe-se, desse modo, a aderência à ideia de que a representação que se faz de um conceito refere-se a um deslocamento, ou seja, uma apropriação temporária, podendo sofrer alterações em sua forma de representação. Assim, qualquer alteração nos limites de um conceito acarretaria uma modificação nos conceitos vizinhos e consequentemente nos termos que os expressam. Essa representação, desde que delimitada por em um domínio específico de conhecimento, relativizaria a ideia da generalidade.

Observa-se a rejeição dos autores aos argumentos defensores das formas neutras de relacionamento entre conceitos e termos, livres de julgamentos de valor ou ideologias, descartando previamente todas as pré-noções e preconceitos. Entretanto, nem sempre é explicitada a necessidade de compreensão dos termos em função não somente do conceito que eles representam, mas da constelação de outros termos e das mudanças históricas que seu emprego demanda, conforme a dinâmica que produz as interações reais entre conceitos e termos. 


\section{REFERÊNCIAS}

AFONSO, J. S. Comunicação e teoria da tradução. 1997. Dissertação (Mestrado em Ciências da Comunicação)- Universidade da Beira Interior, Portugal, 1997. Disponível em: < http://www.prof2000.pt/users/jsafonso/tese.htm >. Acesso em 02 ago. 2011.

BAKHTIN, M. (VOLOCHINOV). Marxismo e filosofia da linguagem. 10. ed. São Paulo: Hucitec, 2004.

BOURDIEU, P. La noblesse d'État: grandes écoles et esprit de corps. Paris: Minuit, 1989.

CHOMSKY, N. Sobre natureza e linguagem. São Paulo: Hermes Fontes, 2006.

DAHLBERG, I. Fundamentos teórico-conceituais da classificação. Revista de Biblioteconomia de Brasília, Brasília, v. 6, n. 1, p. 9-21, jan.jun. 1978a.

DAHLBERG, I. Teoria do conceito. Ciência da Informação, Brasília, v. 7, n. 2, p. 101-107, 1978b.

DATTA, S. A organização de conceitos para recuperação da informação. Ciência da Informação, Brasília, v. 6, n. 1, p. 17-28, 1977.

DODEBEI, V. L. D. Tesauro: linguagem de representação da memória documentária. Niterói: Intertexto; Rio de Janeiro: Interciência, 2002.

FREGE, G. Begriffsschrift, English translation in J. van Heijenoort, From Frege to Gödel, Harvard University Press, Cambridge, MA, p. 1-82, 1967.

FUJITA, M. S. L.; RUBI, M. P. Elementos de política de indexação em manuais de indexação de sistemas de informação especializados. In: ENCONTRO DE DIRETORES E $\checkmark$ ENCONTRO DE DOCENTES DE BIBLIOTECONOMIA E CIÊNCIA DA INFORMAÇÃO DO MERCOSUL, 6., 2002, Londrina, Resumos. Londrina: UEL, 2002.

HESSEN, J. Teoria do conhecimento. São Paulo: Martins Fontes, 2003.

HOBSBAWM, E. J. A era das revoluções: Europa 1789-1848. Rio de Janeiro: Paz e Terra, 1977.

KHLYABICH, I. Pequena história da filosofia e Dicionário dos principais termos filosóficos. São Paulo: Argumentos, 1967.

JANNUZZI, C. A. S. C. Informação tecnológica e para negócios no Brasil: introdução ao uso de conceitos e terminologias. Transinformação, Campinas, v. 9, n. 3, p. 159-160, set./dez. 1997.

LEACH, E. Cultura e comunicação: a lógica pela qual os símbolos estão ligados. Rio de Janeiro: Zahar, 1978.

LUKÁCS, G. Prolegômenos para uma ontologia do ser social: questões e princípios para uma ontologia hoje tornada possível. São Paulo: Boitempo, 2010. 
NUNES, L.; MURGUIA, E. I. Epistemologia da Ciência da Informação: o GT 1 do Enancib em foco. In: ENCONTRO NACIONAL DE PESQUISA EM CIÊNCIA DA INFORMAÇÃO, 10., 2009, João Pessoa, PB. Anais... João Pessoa, PB: Ideia, 2009.

OLIVEIRA, M. B. Popper e seus dois problemas da demarcação. Cadernos de História e Filosofia da Educação, v. 2, n. 4, p. 43-53, 1998.

OLIVEIRA, M. B. Sobre o significado político do positivismo lógico. Campinas, 2010. Disponível em: <www.unicamp.br/cemarx/criticamarxista/C_Marcos.pdf >. Acesso em: 20 mar. 2011.

PEIRCE, C.S. Semiótica e Filosofia. São Paulo: Cultrix, 1977.

WHITNEY, W. D. A vida da linguagem. Petrópolis, RJ: Vozes, 2010.

WILLIAMS, R. O campo e a cidade na história e na literatura. São Paulo: Companhia das Letras, 2011.

WITTGENSTEIN, L. Tractatus logico-philosophicus. 2. ed. São Paulo: Edusp, 1994.

\section{APÊNDICE}

AGANETTE, E.; ALVARENGA, L.; SOUZA, R. R. Elementos constitutivos do conceito de Taxonomia. Informação \& Sociedade: Estudos, João Pessoa, v. 20, n. 3, p. 77-93, set./dez. 2010.

ALVARENGA, L. A teoria do conceito revisitada em conexão com ontologias e metadados no contexto das bibliotecas tradicionais e digitais. DataGramaZero, Rio de Janeiro, v. 2, n. 6, dez. 2001.

AZEVEDO NETTO, C. X. A abordagem do conceito como uma estrutura semiótica. Transinformação, Campinas, v. 20, n. 1, p. 47-58, jan./abr. 2008.

AZEVEDO NETTO, C. X. Signo, sinal, informação: as relações de construção e transferência de significados. Informação \& Sociedade: Estudos, João Pessoa, v. 12, n. 2, p. 01-13, 2002.

BELLUZZO, R. C. B. O uso de mapas conceituais e mentais como tecnologia de apoio à gestão da informação e da comunicação: uma área interdisciplinar da competência em informação. Revista Brasileira de Biblioteconomia e Documentação, São Paulo, v. 2, n. 2, jul./dez. 2006.

BEPPLER, F. D.; FONSECA, F. T.; PACHECO, R. C. S. Hermeneus: um Framework para recuperação e busca de informação. DataGramaZero, Rio de Janeiro, v. 10, n. 2, abr. 2009.

BIOLCHINI, J. C. A. Semântica e cognição em bases de conhecimento: do vocabulário controlado à ontologia. DataGramaZero, Rio de Janeiro, v. 2, n. 5, out. 2001. 
CAMPOS, M. L. A. Linguagens documentárias: núcleo básico de conhecimento para seu estudo. Revista da Escola de Biblioteconomia da UFMG, Belo Horizonte, v. 24, n. 1, p. 5262, jan./jun. 1995.

CAMPOS, M. L. A. Perspectivas para o estudo da área de representação da informação. Ciência da Informação, Brasília, v. 25, n. 2, p. 1-7, maio/ago. 1996.

CAMPOS, M. L. A.; CAMPOS, M. L. M.; SOUZA, R. F. Organização de unidades de conhecimento em hiperdocumentos: o modelo conceitual como espaço comunicacional para a realização da autoria. Ciência da Informação, Brasília, v. 32, n. 2, p. 7-16, maio/ago. 2003.

CAMPOS, M. L. A.; GOMES, H. E. Metodologia de elaboração de tesauro conceitual: a categorização como princípio norteador. Perspectivas em Ciência da Informação, Belo Horizonte, v. 11, n. 3, p. 348-359, set./dez. 2006.

CAMPOS, M. L. A.; GOMES, H. E. Princípios de Organização e Representação do Conhecimento na Construção de Hiperdocumentos. DataGramaZero, Rio de Janeiro, v. 6, n. 6, dez. 2005.

CAMPOS, M. L. A.; GOMES, H. E. Taxonomia e Classificação: o princípio de categorização. DataGramaZero, Rio de Janeiro, v. 9, n. 4, ago. 2008.

CAMPOS, M. L. A. Modelização de domínios de conhecimento: uma investigação de princípios fundamentais. Ciência da Informação, Brasília, v. 33, n. 1, p. 22-32, jan./abr. 2004.

CARVALHO, A. O.; CARVALHO, M. B. P. A Semântica e a Classificação Decimal Universal. Ciência da Informação, Brasília, v. 4, n. 2, p. 91-102, 1975.

CATARINO, M. E.; BAPTISTA, A. A. Folksonomia: um novo conceito para a organização dos recursos digitais na Web. DataGramaZero, Rio de Janeiro, v. 8, n. 3, jun. 2007.

CAVALCANTI, C. R. Indexação. Estudos Avançados em Biblioteconomia e Ciência da Informação, Brasília, v. 1, n. 1, p. 211-233, 1982.

CHAUMIER, J. Indexação: conceito, etapas e instrumentos. Revista Brasileira de Biblioteconomia e Documentação, São Paulo, v. 21, n. 1/2, jan./jun. 1988.

COSTA, I. T. M. Memória institucional e representação: do mundo das formas (árvore) ao universo do pensamento (Rizoma). Informare, Rio de Janeiro, v. 2, n. 2, jul./dez. 1996.

DAHLBERG, I. Fundamentos teórico-conceituais da classificação. Revista de Biblioteconomia de Brasília, Brasília, v. 6, n. 1, p. 9-21, jan./jun. 1978b.

DAHLBERG, I. Teoria do conceito. Ciência da Informação, Brasília, v. 7, n. 2, p. 101-107, 1978b.

DATTA, S. A organização de conceitos para recuperação da informação. Ciência da Informação, Brasília, v. 6, n. 1, p. 17-28, 1977.

DIAS, C. A. Terminologia: conceitos e aplicações. Ciência da Informação, Brasília, v. 29, n. 1 , p. $90-92$, jan./abr. 2000. 
DUARTE, E. A. Classificação facetada: um olhar sobre a construção de estruturas semânticas. Revista Digital de Biblioteconomia \& Ciência da Informação, Campinas, v. 7, n. 2, p. 46-58, jan./jun. 2010.

DUARTE, E. A.; CERQUEIRA, R. F. P. Análise facetada: um olhar face a modelagem conceitual. Revista Digital de Biblioteconomia \& Ciência da Informação, Campinas, v. 4, n. 2, p. 39-52, jan./jun. 2007.

FACHIN, G. R. B. Recuperação inteligente da informação e ontologias: um levantamento na área da Ciência da Informação. BIBLOS - Revista do Instituto de Ciências Humanas e da Informação, Rio Grande, v. 23, n. 1, p. 259-283, 2009.

FRANCELIN, M. M. Conceitos, domínios do saber e fronteiras epistemológicas. Revista Digital de Biblioteconomia \& Ciência da Informação, Campinas, v. 8, n. 2, p. 152-165, jan./jun. 2011.

FUJITA, M. S. L. A identificação de conceitos no processo de análise de assunto para indexação. Revista Digital de Biblioteconomia \& Ciência da Informação, Campinas, v. 1, n. 1, p. 60-90, jul./dez. 2003.

FUJITA, M. S. L. A Leitura Documentária na perspectiva de suas variáveis: leitor-textocontexto. DataGramaZero, Rio de Janeiro, v. 5, n. 4, ago. 2004.

GALVÃO, M. C. B. Construção de conceitos no campo da ciência da informação. Ciência da Informação, Brasília, v. 27, n. 1, p. 46-52, jan./abr. 1998.

GOMES, H. E.; CAMPOS, M. L. A.; GUIMARÃES, L. S. Organização da Informação e Terminologia: a abordagem onomasiológica. DataGramaZero, Rio de Janeiro, v. 11, n. 5, p. $01-12$, out./2010.

GOMES, H. E.; CAMPOS, M. L. A. Tesauro e normalização terminológica: o termo como base para intercâmbio de informações. DataGramaZero, Rio de Janeiro, v. 5, n. 6, p. 00, dez. 2004.

GONZÁlEZ DE GÓMEZ, M. N. Informação e conhecimento. Ciência da Informação, Brasília, v. 13, n. 2, p. 107-114, jul./dez. 1984.

GRACIOSO, L. S. Parâmetros teóricos para elaboração de instrumentos pragmáticos de representação e organização da informação na Web: considerações preliminares sobre uma possível proposta metodológica. InCID: Revista de Ciência da Informação e Documentação, Ribeirão Preto, v. 1, n. 1, p. 138-158, 2010.

GUEDES, R. M.; DIAS, E. J. W. Indexação social: abordagem conceitual. Revista ACB: Biblioteconomia em Santa Catarina, Florianópolis, v. 15, n. 1, p. 39-53, jan./jun. 2010.

GUIMARÃES, J. A. C.; SALES, R. Análise documental: concepções do universo acadêmico brasileiro em Ciência da Informação. DataGramaZero, Rio de Janeiro, v. 11, n. 1, fev./2010.

JANNUZZI, C. A. S. C. Informação tecnológica e para negócios no Brasil: introdução ao uso de conceitos e terminologias. Transinformação, Campinas, v. 9, n. 3, p. 159-160, set./dez. 1997. 
LARA, M. L. G. Linguagem documentária e terminologia. Transinformação, Campinas, v. 16, n. 3, p. 231-240, set./dez. 2004.

LARA, M. L. G. O unicórnio (o rinoceronte, o ornitorrinco...), a análise documentária e a linguagem documentária. DataGramaZero, Rio de Janeiro, v. 2, n. 6, dez. 2001.

LIMA, G. Â. B. de O. A análise facetada na modelagem conceitual de sistemas de hipertexto: uma revisão de literatura. Perspectivas em Ciência da Informação, Belo Horizonte, v. 7, n. 2, p. 189-196, jul./dez. 2002.

LIMA, G. Â. B. de O. A análise facetada na modelagem conceitual para organização hipertextual de documentos acadêmicos: sua aplicação no prototipo MHTX (mapa hipertextual). Informação \& Sociedade: Estudos, João Pessoa, v. 17, n. 1, p. 31-41, jan./abr. 2007a.

LIMA, G. Â. B. de O. Modelo hipertextual - MHTX: um modelo para organização hipertextual de documentos. DataGramaZero, Rio de Janeiro, v. 8, n. 4, ago. 2007a.

MARI, H. Dos fundamentos da significação à produção do sentido. Perspectivas em Ciência da Informação, Belo Horizonte, v. 1, n. 1, p. 93-109, jan./jun. 2007b.

MARQUES, S. A.; SIQUEIRA, R. Thesaurus Multidisciplinar: Estrutura Básica. Cadernos de Biblioteconomia, Recife, v. 6, n. 1, p. 100-115, jun. 1983.

MEDEIROS, J. S. A construção do conceito: aproximações complementares entre a análise de Michel Foucault e Ingetraut Dahlberg. Revista ACB: Biblioteconomia em Santa Catarina, Florianópolis, v. 15, n. 2, p. 40-53, jul./dez. 2010.

MENDONÇA, E. S. A lingüística e a ciência da informação: estudos de uma interseção. Ciência da Informação, Brasília, v. 29, n. 3, p. 50-70, set./dez. 2000.

MORAES, A. F.; ARCELLO, E. N. O conhecimento e sua representação. Informação \& Sociedade: Estudos, João Pessoa, v. 10, n. 2, p. 105-121, 2000.

MOREIRA, A. Contribuição da terminologia na modelagem de sistemas computacionais. DataGramaZero, Rio de Janeiro, v. 6, n. 5, out. 2005.

MOREIRA, A.; ALVARENGA, L.; OLIVEIRA, A. P. O nível do conhecimento e os instrumentos de representação: tesauros e ontologias. DataGramaZero, Rio de Janeiro, v. 5, n. 6, dez. 2004.

MOREIRO GONZÁLEZ, J. A. Evolução ontológica das linguagens documentárias. Relato de uma experiência de curso organizado conjuntamente para o DT/SIBI-USP e o PPGCI/ECA. InCID: Revista de Ciência da Informação e Documentação, Ribeirão Preto, v. 2, n. 1, 2011.

MOSTAFA, S. P.; CRUZ, D. V. N. A importância do empirismo inglês para as linguagens documentárias. DataGramaZero, Rio de Janeiro, v. 11, n. 2, abr./2010.

MOURA, M. A. Informação, ferramentas ontológicas e redes sociais ad hoc: a interoperabilidade na construção de tesauros e ontologias. Informação \& Sociedade: Estudos, João Pessoa, v. 19, n. 1, p. 59-73, jan./abr. 2009. 
MUCHERONI, M. L.; PAIVA, D. C.; LOBBO NETTO, M. Três ontologias clássicas e a web semântica. Ponto de Acesso, Salvador, v. 3, n. 3, p. 281-298, jul./dez. 2009.

NAVES, M. M. L. Análise de assunto: concepções. Revista de Biblioteconomia de Brasília, Brasília, v. 20, n. 2, p. 215-226, jul./dez. 1996.

NONATO, R. S.; LIMA, G. Â. B. O. Determinação de links hipertextuais: uma abordagem da ciência da informação. Informação \& Sociedade: Estudos, João Pessoa, v. 18, n. 1, p. 197-205, jan./abr. 2008.

NOVO, H. F. A taxonomia enquanto estrutura classificatória: uma aplicação em domínio de conhecimento interdisciplinar. Ponto de Acesso, Salvador, v. 4, n. 2, p. 131-156, ago./set. 2010.

NUNES, C. O. L. Análise documentária: os limites da univocidade. BIBLOS - Revista do Instituto de Ciências Humanas e da Informação v. 14, 2002.

NUNES, L.; TÁLAMO, M. F. G. M. Da filosofia da classificação à classificação bibliográfica. Revista Digital de Biblioteconomia \& Ciência da Informação, Campinas, v. 7, n. 1, p. 30-48, jul./dec. 2009.

PEREIRA, E. C.; BUFREM, L. S. Princípios de organização e representação de conceitos em linguagens documentárias. Encontros Bibli: Revista Eletrônica de Biblioteconomia e Ciência da Informação, Florianópolis, v. 10, n. 20, p. 21-37, 2 sem. 2005.

RAUTENBERG, S.; TODESCO, J. L.; STEIL, A. V. Ontologias de domínio no mapeamento de instrumentos da gestão do conhecimento e de agentes computacionais da engenharia do conhecimento: o estado da arte. Perspectivas em Ciência da Informação, Belo Horizonte, v. 15, n. 2, p. 163-182, maio/ago. 2010.

RENDÓN-RÓJAS, M. A. Relación entre los conceptos: información, conocimiento y valor. Semejanzas y diferencias. Ciência da Informação, Brasília, v. 34, n. 2, p. 52-61, maio/ago. 2005.

ROBREDO, J. Otimização dos processos de indexação dos documentos e de recuperação da informação mediante o uso de instrumentos de controle terminológico. Ciência da Informação, Brasília, v. 11, n. 1, p. 3-18, 1982.

RODRIGUES, A. Uma estrutura de classificação com enfoque na cultura amazônica. Ciência da Informação, Brasília, v. 34, n. 2, p. 43-51, maio/ago. 2005.

SALDANHA, G. S. Tradições epistemológicas nos estudos de organização dos saberes: uma leitura histórico-epistêmica a partir da filosofia da linguagem. Liinc em revista, Rio de Janeiro, v. 6, n. 2, p. 300-315, 2010.

SALES, R.; CAFÉ, L. Diferenças entre Tesauros e Ontologias. Perspectivas em Ciência da Informação, Belo Horizonte, v. 14, n. 1, p. 99-116, jan./abr. 2009.

SALES, R; CAFÉ, L. Semelhanças e diferenças entre tesauros e ontologias. DataGramaZero, Rio de Janeiro, v. 9, n. 4, ago. 2008. 
SANTAREM-SEGUNDO, J. E.; VIDOTTI, S. A. B. G. Rede de tags para recuperação da informação no contexto da Representação Iterativa. InCID: Revista de Ciência da Informação e Documentação, Ribeirão Preto, v. 2, n. 1, 2011.

SCHIESSL, M. Ontologia: o termo e a idéia. Encontros Bibli: Revista Eletrônica de Biblioteconomia e Ciência da Informação, Florianópolis, v. 12, n. 24, p. 172-181, 2º sem. 2007.

SILVA, M. A.; OLIVEIRA, E. S. G. Mapas conceituais e aprendizagem no ciberespaço: uma reflexão sobre didática e partituras musicais. ETD - Educação Temática Digital, Campinas, v. 8, n. 1, p. 72-89, dez. 2006.

SIQUEIRA, J. C. O Conceito Classificação: Uma Abordagem Histórica e Epistemológica. Revista Brasileira de Biblioteconomia e Documentação, São Paulo, v. 6, n. 1, p. 37-49, 2010.

STREHL, L. As folksonomias entre os conceitos e os pontos de acesso: as funções de descritores, citações e marcadores nos sistemas de recuperação da informação. Perspectivas em Ciência da Informação, Belo Horizonte, v. 16, n. 2, p. 101-114, 2011.

TÁLAMO, M. F. G. M.; LARA, M. L. G. Interfaces between linguistics, terminology and documentation. Brazilian Journal of Information Science, Marilia, v. 3, n. 2, p. 54-70, jul./dez. 2009.

UNISIST. Princípios de indexação. Revista da Escola de Biblioteconomia da UFMG, Belo Horizonte, v. 10, n. 1, p. 83-94, mar. 1981.

VITAL, L. P.; CAFE, L. M. A. Ontologias e taxonomias: reflexões conceituais. Perspectivas em Ciência da Informação, Belo Horizonte, v. 16, n. 2, p. 115-130, 2011.

VOGEL, M. J. M. A influência da Jean-Claude Gardin e a linha francesa na evolução do conceito de linguagem documentária. Perspectivas em Ciência da Informação, Belo Horizonte, v. 14, n. esp., nov. 2009.

\title{
Title
}

Concept appropriation as an object in the scientific periodical literature in information science

\begin{abstract}
It analyses the notion of concept situated in the periodical literature in Information Science in Brazil. It discusses the theoretical ideas about the concept and its relations with the historical process that determines itself, and indicates possibilities of studies related to the semantic fields in which these relations are carried out. It analyzes the contents of a corpus of 75 articles selected from the "Base Referencial de Artigos de Periódicos em Ciência da Informação (Brapci)", between the years 1975 and 2011, identifying and mapping themes related to the conception and evolution of the concept as an object of study. The concept is widely discussed in relation to its philosophical origins, its relations with science and reality, but it has not been sufficiently explored in relation to the richness and connotations that it acquires historically, to the ideology or the power relations existing in the semantic fields in which it is represented and defined.
\end{abstract}




\section{Keywords}

Concept. Concept theory. Terminology. Conceptual model.

\section{Título}

La apropiación del concepto en cuanto objeto de la literatura científica en Ciencia de la Información

\section{Resumen}

Este trabajo examina la noción de concepto situada en las publicaciones periódicas en ciencias de la información en Brasil. Analiza las concepciones teóricas sobre el concepto y su relación con el proceso histórico que las determina, indicando las posibilidades de estudios de los campos semánticos en que estas relaciones se efectúan. Analiza, también, el contenido de un corpus de 75 artículos seleccionados de la Base de Referencia de Artículos de Revistas en Ciencias de la Información (Brapci) entre los años 1975 y 2011, procediendo la identificación y mapeo de temas relacionados con el diseño y la evolución del concepto como un objeto estudio. El concepto es ampliamente discutido en relación a sus orígenes filosóficos, sus relaciones con la ciencia y la realidad, pero no ha sido suficientemente explorado en lo referente a la riqueza y a las connotaciones que adquiere históricamente, a la ideología o a las relaciones de fuerza existentes en los campos semánticos en los que está representado y definido

\section{Palabras clave}

Concepto. Teoría del concepto. Terminología. Modelo conceptual.

Recebido em: 16/09/2011

Aceito em: 07/12/2011 